\title{
Negative Parental Responses to Coming Out and Family Functioning in a Sample of Lesbian and Gay Young Adults
}

\author{
Roberto Baiocco - Lilybeth Fontanesi - Federica Santamaria - Salvatore Ioverno • \\ Barbara Marasco • Emma Baumgartner • Brian L. B. Willoughby • \\ Fiorenzo Laghi
}

Published online: 27 March 2014

(c) Springer Science+Business Media New York 2014

\begin{abstract}
Parental responses to youths' coming out (CO) are crucial to the subsequent adjustment of children and family. The present study investigated the negative parental reaction to the disclosure of same-sex attraction and the differences between maternal and paternal responses, as reported by their homosexual daughters and sons. Participants' perceptions of their parents' reactions (evaluated through the Perceived Parental Reactions Scale, PPRS), age at CO, gender, parental political orientation, and religiosity involvement, the family functioning (assessed through the Family Adaptability and Cohesion Evaluation Scales), were assessed in 164 Italian gay and lesbian young adults. Pearson correlation coefficients were calculated to assess the relation between family functioning and parental reaction to CO. The paired sample $t$ test was used to compare mothers and fathers' scores on the PPRS. Hierarchical multiple regression was conducted to analyze the relevance of each variable. No differences were found between mothers and fathers in their reaction to the disclosure. The analysis showed that a negative reaction to $\mathrm{CO}$ was predicted by parents' right-wing political conservatism, strong religious beliefs, and higher scores in the
\end{abstract}

R. Baiocco $(\bowtie) \cdot$ L. Fontanesi - S. Ioverno - B. Marasco .

E. Baumgartner · F. Laghi

Department of Developmental and Social Psychology, Faculty of

Medicine and Psychology, Sapienza University of Rome, Rome,

Italy

e-mail: roberto.baiocco@uniroma1.it

F. Santamaria

Department of Psychology, Faculty of Education, University of Messina, Messina, Italy

B. L. B. Willoughby

Department of Psychology, University of Miami, Coral Gables, FL, USA scales Rigid and Enmeshed. Findings confirm that a negative parental reaction is the result of poor family resources to face a stressful situation and a strong belief in traditional values. These results have important implications in both clinical and social fields.

Keywords Coming out - Disclosure - Lesbian and gay young adults $\cdot$ Parental reactions $\cdot$ Family functioning

\section{Introduction}

The coming-out $(\mathrm{CO})$ process, defined as the sharing of one's sexual orientation with others, has been described as an essential component in lesbian and gay (LG) identity formation and integration (Cass 1979; Legate et al. 2012). Identity integration includes acceptance of one's gay, lesbian, or bisexual identity, and sharing this aspect of the self with other individuals. Previous researches have indicated that $\mathrm{CO}$ process may have positive effects on relationships with others (e.g., improving authenticity of a friendship), the construction of self-identity, and mental health (e.g., decreased hypervigilance/anxiety) (Baiocco et al. 2012; Shilo and Savaya 2011; Vaughan and Waehler 2010).

Erikson's model of sexual identity development (1959, 1982) posits that certain stages and "tasks" must be navigated successfully to form a healthy personality. These eight steps go through the implementation of tasks concerning trust, differentiation, autonomy and the management of doubts, fear and conflict, inside the family and the society (Erikson 1982). According to this point of view, $\mathrm{CO}$ can be assimilated into a developmental task. For LG adolescents, this process may be growth-enhancing event and is highly important to developing an integrated identity and for strengthening self-esteem (Henry 2013). Such 
experiences of growth may provide sexual minorities with important strengths that can be used to effectively manage stress related to their minority status (Lingiardi et al. 2012; Meyer 1995, 2003). However, despite the potential benefits of $\mathrm{CO}$, there are also associated stressors, which can have a deleterious impact on physical and psychological health (Frost et al. 2013). These stressors can include family rejection, bullying, discrimination and prejudices (Frost et al. 2013; Guzzo et al. 2014). The CO process may also place significant strain on family relationships, cause interparental conflict, and exacerbate parent mental health issues (e.g., Willoughby et al. 2008). Given this, a strong and cohesive family, displaying adequate resources to manage stressful situations, may provide a supportive environment for the LG adolescent who decides to come out. The majority of LG young people often do not have access to positive models (i.e., parents often do not share the same sexual orientation) and their families may reject their sexual orientation (Bos et al. 2004). In the American context, research indicate that as many as $52 \%$ of parents may initially react negatively to their child's disclosure of same sex attractions (D'augelli et al. 2008). The negative consequences of rejecting reactions from parents range from depression (Legate et al. 2012), negative LG identity (Willoughby et al. 2010), and substance abuse (Baiocco et al. 2010) to, in some extreme cases, suicide (Ryan et al. 2009). On the other hand, a supportive and positive family environment is associated with positive young adult health outcomes, such as low level of internalized sexual stigma, depression and suicidal idealization, and high level of social support and self-esteem (Baiocco et al. 2012; D'Augelli and Grossman 2001; Hoffman et al. 2009; Lo Cascio et al. 2013; Pace et al. 2012; Resnick et al. 1997; Russell 2003; Ryan et al. 2010).

Italy, where the present study was conducted, is a family-oriented society in which adolescents and young adults are more extensively involved with their extended families than members of other Western societies (Baiocco et al. 2013; Pallini and Laghi 2012). LG men in Italy frequently confront a roster of biases and prejudices and a greater level of gender segregation in their daily lives (Lingiardi et al. 2012). Previous studies in Italy, in fact, have found high levels of internalized sexual stigma in gay and lesbian adolescents and young adults (Baiocco et al. 2010, 2012; Lingiardi et al. 2012). Thus, a supportive family environment becomes extremely significant, since Italian culture is characterized by a great level of gender segregation. Widespread heterosexism in society establishes that the only normatively acceptable sexual behaviors are heterosexual (Herek and Garnets 2007). In Italy, LG adolescents and young adults encounter many difficulties and may be afraid of disclosing their sexual orientation because of unfavorable outcomes such as social rejection and discrimination, which are realistic possibilities.

Parental rejection at the time of disclosure is a strong, negative event that can affect all aspects of an adolescent's life, and it is crucial to understand how this reaction is elicited and how to support parent, child, and family adjustment following the disclosure. This process is well described by the Family Stress Theory (Patterson 2002), developed with the purpose of explaining how and why stressful events negatively affect the wellbeing of the family and, as already underlined, the disclosure could be one of these events.

According to this theory, within which the present research is developed, parental reactions to $\mathrm{CO}$ is the result of three main elements: a family's relational capabilities and competences, family members' beliefs about meanings of stressful events, and the amount of stressors that undermine family stability (Willoughby et al. 2008). Family-based resources, such as cohesion, adaptability, and flexibility, may represent valuable predictors to understand how the family will react to their child's CO (Carnelley et al. 2011). The literature underlines how families, with adequate relational capacities, coping abilities, and a higher level of resilience, often face difficult events in supportive ways, such as displaying a more positive reaction to their sons and daughters' sexual orientation disclosures (Lavee and Olson 1991; Willoughby et al. 2006).

As mentioned above, CO to family, especially to parents, is often the biggest challenge for same-sex attracted young people (Savin-Williams 2005; Savin-Williams and Ream 2003; Savin-Williams and Dube 1998). However, despite the risk of disapproval and victimization, the majority of gay and lesbian adolescents decide to come out to their parents (LaSala 2000). A handful of studies (BenAri 1995; D'Augelli et al. 2002; LaSala 2000; Saltzburg 2004; Savin-Williams 2001; Willoughby et al. 2006) have examined parents' initial reactions to their youth's CO. Literature underlines the relevance of the following variables for predicting parents' negative reactions to $\mathrm{CO}$ : parental age (i.e., older parents react more negatively; Baiocco et al. 2013; Savin-Williams 2001), lower levels of parental education (Conley 2011), involvement in traditional religious associations (Baiocco et al. 2013b; Schope 2002), traditional values about family and marriage (Newman and Muzzonigro 1993), and more traditional attitudes regarding sex roles (Cramer and Roach 1988). Concerning those factors, parental reaction is affected by the meaning each member of the family gives to the disclosure. This process involves not only religious beliefs, political ideology, but also cultural and educational backgrounds. If one or both parents hold preexisting negative beliefs and values about homosexuality, then they may be repulsed by the disclosure (Cramer and Roach 1988). More 
specifically, these beliefs affect their personal beliefs about the causes of homosexuality: believing that homosexuality is learned rather than, for example, genetic; holding gay and lesbian individuals responsible for their lifestyle; and supposing they have some control over their sexual orientation (Sakalli 2002).

Findings indicate fathers' and mothers' may react differently to their child's CO. Several studies reveal that mothers were likely to respond more positively to disclosure than fathers (Armesto and Weisman 2001; Ben-Ari 1995; Boxer et al. 1991; D'Augelli and Hershberger 1993; D'Augelli et al. 2002; Maguen et al. 2002; Savin-Williams and Dube 1998). Some studies, however, have found that mothers may be perceived to react more negatively than fathers (Willoughby et al. 2006), show greater concerns/ worries (Conley 2011), and a display a greater amount of anger and guilt than fathers.

Regarding differences in reactions to the $\mathrm{CO}$ of lesbian daughters versus gay sons, Conley (2011) found that parents' overall concern was higher for gay sons. In addition, referring to youth characteristics that are predictive of parental reactions, some studies found that reaction was more negative when the child was of the same gender as the parent (D'Augelli 2006), and more negative for younger adolescents than older adolescents and young adults (LaSala 2000). However, others studies did not confirm these findings (D'Augelli et al. 2005; Heatherington and Lavner 2008).

From a systemic point of view, disclosure has been defined a "whole family experience" (Baptist and Allen 2008) and a phenomenon that is "interpersonal in nature" (Mohr and Fassinger 2003), pointing out that it is a salient event involving all family members. The family, as a system, may be an important predictor of parental reactions to sexual orientation disclosure (LaSala 2000). According to the Family Stress Theory, parent-child relationships and pre-existing resources can buffer the effects of an event that shifts several aspects of the family system, such as expectations and desires, and can lead to adopting new roles inside the family. Additional variables related to the outcome within the family include: pre-existing level of closeness and conflict in the parent-child dyad, the time spent together, importance of parents as a source of social support (Heatherington and Lavner 2008), economic independence (Gardner et al. 2014), availability of other sources of support (Chaudoir and Fisher 2010), and individuals' assessment of the cost/benefit for themselves and for their parents (Green 2000).

Understanding the $\mathrm{CO}$ process and the variables related to a negative family response is an important aspect for the design and delivery of LG youth services. The present research examines the different parental responses to the $\mathrm{CO}$ of youths, and the elements associated with parents' reactions, from the perspective of their daughters and sons. The current study aims to identify the differences between mothers' and fathers' responses, and the individual factors that can affect, positively or negatively, how parents are perceived to react to their child's disclosure. The specific research questions addressed in this study are as follows: (a) do perceptions of reactions to $\mathrm{CO}$ differ for mothers versus fathers and (b) are perceived parental reactions related to the gender and the age of the son/ daughter. We expected that a more negative parental response is related to younger ages of the children and, when the child's sex is the same of his/her parent (D'Augelli 2006; LaSala 2000; Saltzburg 2004; Savin-Williams 2001). The current study also addresses these additional questions: (c) does parental religious beliefs and political conservatism predict perceived parental reactions (Cramer and Roach 1988; Newman and Muzzonigro 1993; Schope 2002) and (d) is problematic family functioning predictive of more negative perceived parental reactions to CO (De Vine 1984; Willoughby et al. 2006).

\section{Method}

\section{Participants}

Data were collected for 164 participants: 71 women $(43.3 \%)$ and 93 men (56.7\%), who self-identified as gay or lesbian, based on the Kinsey Scale (Kinsey et al. 1948). Nearly half, or $46.1 \%$, of the young adults came from the center of Italy, $30.4 \%$ from the south, and the $24.5 \%$ from the north of Italy. In this study, we did not include bisexual (3.7\%) and transgender participants $(1.2 \%)$, due to the low number of respondents in these categories. Participants' ages ranged from 18 to $26\left(M_{\text {woman }}=23.21\right.$, $\left.S D=1.97 ; \quad M_{\text {men }}=23.41, \quad S D=2.15\right) . \quad$ Participants averaged 15 years of education, which means they reported completing the second year of college $\left(M_{\text {woman }}=14.72\right.$, $\left.S D=3.11 ; M_{\text {men }}=15.25, S D=2.64\right)$.

\section{Procedures}

Participants were recruited from lesbian, gay, bisexual, and transgender (LGBT) organizations (31\%) and three LGBT college student organizations $(69 \%)$ in Rome, Italy. The prerequisites for inclusion were: Respond to the Kinsey Scale at level 5 and 6 (where 5 meaning almost completely and 6 meaning completely homosexual); be between 18 and 26 years old; have already revealed their sexual orientation to both parents; be Italian; and, finally, the parents had to be a couple and to living together (not divorced or separated) at the time of CO. All participants responded individually to the same questionnaire packet, which was administered face-to-face by trained psychologists. 
Participation in the study was voluntary and anonymous, and participants were encouraged to answer as truthfully as possible. The participants took about $20-25$ min to complete the questionnaires. A total of $98.1 \%$ of questionnaires were completed. Before the data collection was started, the protocol was approved by the Ethics Commission of the Department of Developmental and Social Psychology of the Sapienza University of Rome.

\section{Measures}

A Background Information Questionnaire was completed by participants. Demographic information, like age, education, religion, and disclosure status was collected. Sexual orientation was evaluated using the Kinsey Scale (Kinsey et al. 1948). This scale offers six possibilities, ranging from 0 (people who defined themselves as completely heterosexual, without any experience or desire for homosexual activity) to 6 (those who declared themselves as exclusively homosexual). Data about parents' level of education and religious affiliation were collected as well. Moreover, we asked participants to report the age at which they came out to parents and to describe the way in which their parents knew/discovered their sexual orientation ("How did your mother/ father discover your sexual orientation?"; 1 = I personally told it to my mother/father; $2=$ My mother/father asked me about my sexual orientation; $3=$ My mother/father discovered it; $4=$ Other persons revealed my sexual orientation to my mother/father).

Parents Religiosity Involvement was measured by two items, asking participants to report the frequency of their parents' attendance of religious service ("How often does your mother/father usually attend religious services?"; $0=$ never, $10=$ several times per week), as well as the importance of religion in their parents' lives ("How important is religion in your father life/mother life?"; $0=$ not important, $10=$ extremely Important). Since the correlation between these two items was high $(r=.72)$, a total score was obtained by summing the responses to each item, which we considered as a general measure of parents' religiosity involvement (Roth et al. 2012).

Political orientation was measured by asking participants to report the political orientation of the parents on a 5-point Likert Scale ranging from $1=$ completely left to $5=$ completely right, so that higher scores indicated greater right-wing conservatism.

The Perceived Parental Reactions Scale (PPRS; Willoughby et al. 2006) assessed participants' perceptions of their parents' reactions to sexual orientation disclosure. Participants were asked to think back to the time when disclosure occurred and, using a 5-point Likert scale, indicate agreement or disagreement with several statements. PPRS included 64 statements, 32 related to the mother and 32 to the father. Higher scores indicated more negative perceptions of their parents' reactions ("My mom yelled and screamed"), with scores ranging from 32 to 160 . In a previous study (Willoughby et al. 2006), the PPRS showed item-total correlations of .40 and above and demonstrated good internal consistencies. Test-retest reliability has also been established. In the present study, the internal consistency reliability was .95 for the mother version and .86 for the father version.

Family Adaptability and Cohesion Evaluation Scales (FACES IV; Olson 2011) was used to evaluate family functioning of participants. The FACES IV is composed by 42 items (as "Family members are involved in each others lives" or "There is no leadership in this family"). On a Likert-type scale divided into six scales: two balanced scales (Cohesion and Flexibility) assessing central-moderate areas and four unbalanced scales (Rigid, Chaotic, Enmeshed, and Disengaged) assessing the lower and upper ends of Cohesion and Flexibility; family global functioning score was obtained by dividing the sum of the Cohesion and Flexibility scores by 2 (Olson and Gorall 2006). While the two balanced scales are similar to previous FACES III scales, the four Unbalanced Scales-Enmeshed, Disengaged, Chaotic, and Rigid-represent an original improvement (Olson 2011). These scales proved to be valid, reliable, and discriminatory among both problematic and no problematic families (Baiocco et al. 2012; Olson 2011), the original FACES IV internal consistency reliability ranged from .77 to .89 (Olson 2011), in the Italian version range from .63 to .73 (Baiocco et al. 2012). In the present study, the internal consistency reliability range was between .71 and .76 .

\section{Data Analysis}

To conduct bivariate and multivariate analyses relating to independent variables, we used the Statistical Package for the Social Sciences (SPSS 19.0). Pearson correlation coefficients were calculated to assess the relation between family functioning and parental reactions to $\mathrm{CO}$. A paired sample $t$ test was used to compare means scores of mothers and fathers on the Perceived Parental Reaction Scale. Univariate analysis of covariance (ANCOVA) was used to assess differences in gender of the son/daughter and gender of the parents regarding parental reactions using family functioning and age as covariate. Post hoc analyses following ANCOVAs were carried out with Duncan's test to detect group differences $(p<.05)$. Next, hierarchical multiple regressions were conducted to investigate the relevance of family functioning and individual variables to predict parental reactions to $\mathrm{CO}$. 


\section{Results}

\section{Maternal and Paternal Reactions to Coming Out}

Paired sample $t$ test was used to compare means scores of mothers and fathers on Perceived Parental Reactions Scale. No differences were found between mothers $(M=80.93 ; \quad S D=27.86)$ and fathers $(M=75.50$; $S D=30.42)$ in their reaction to the CO of their son/ daughter $\left(\mathrm{t}_{163}=1.54, p=.13\right)$. The correlation between mothers and fathers was high $(\mathrm{r}=.52)$, and the intra-class correlation was significant $(\mathrm{Z}=6.66 ; p<.001)$. In addition, no differences were found between the age of the $\mathrm{CO}$ with the mothers $(M=19.15 ; S D=2.81)$ and fathers $(M=19.45 ; S D=3.11)\left(\mathrm{t}_{163}=1.59, p=.11\right)$. Differences were found between the way in which, according to the participants, the parents discovered the sexual orientation of their daughters/sons $\left(\mathrm{Chi}^{2}=10.32 ; \mathrm{df}=3\right.$; $p<.05)$. The sons/daughters were more likely to reveal their sexual orientation directly to their mothers (mothers: $65.2 \%$; fathers: $55.5 \%$ ) while the fathers discovered the sexual orientation of their sons/daughters on their own (mothers: $17.7 \%$; fathers: $32.3 \%$ ). Mothers were more likely to ask the sexual orientation of their sons/daughters directly than were fathers (mothers: $9.8 \%$; fathers: $5.5 \%$ ). Table 1 shows the frequencies of the answers. Moreover, no differences were found in the frequencies of the answers given by the sons and the daughters about how parents knew/discovered their sexual orientation $\left(\mathrm{Chi}^{2}=6.95\right.$; df $=3 ; p=.07$ ).

Parental Reaction to Coming Out, Religiosity, Political Involvement, and Family Functioning

No differences were found between mothers $(M=2.46$; $S D=.87)$ and fathers $(M=2.57 ; \quad S D=1.67)$. The

Table 1 Frequencies of the way in which parents knew/discovered the sexual orientation of the daughter/son

\begin{tabular}{lccc}
\hline PPRS & Mother & Father & Total \\
\hline $\begin{array}{l}\text { I personally told it to my } \\
\text { mother/father }\end{array}$ & $\begin{array}{c}65.2 \% \\
(\mathrm{n}=107)\end{array}$ & $\begin{array}{c}55.5 \% \\
(\mathrm{n}=91)\end{array}$ & $\begin{array}{c}60.4 \% \\
(\mathrm{n}=198)\end{array}$ \\
$\begin{array}{l}\text { My mother/father asked me } \\
\text { about my sexual }\end{array}$ & $\begin{array}{c}9.8 \% \\
(\mathrm{n}=16)\end{array}$ & $\begin{array}{c}5.5 \% \\
(\mathrm{n}=9)\end{array}$ & $\begin{array}{c}7.6 \% \\
(\mathrm{n}=25)\end{array}$ \\
$\begin{array}{l}\text { orientation } \\
\begin{array}{l}\text { My mother/father } \\
\text { discovered it }\end{array}\end{array}$ & $\begin{array}{c}17.7 \% \\
(\mathrm{n}=29)\end{array}$ & $\begin{array}{c}32.3 \% \\
(\mathrm{n}=53)\end{array}$ & $\begin{array}{c}25.0 \% \\
(\mathrm{n}=82)\end{array}$ \\
$\begin{array}{l}\text { Other persons revealed my } \\
\text { sexual orientation to my } \\
\text { mother/father }\end{array}$ & $\begin{array}{c}7.3 \% \\
(\mathrm{n}=12)\end{array}$ & $\begin{array}{c}6.7 \% \\
(\mathrm{n}=11)\end{array}$ & $\begin{array}{c}7.0 \% \\
(\mathrm{n}=23)\end{array}$ \\
\hline
\end{tabular}

$\mathrm{SD}$ in parenthesis majority of the mothers were positioned on the left side of the scale $(74.4 \%)$, while only $3.7 \%$ were identified as centrist, and $21.9 \%$ were identified as right-wing conservative. Again, the majority of the fathers were positioned on the left side of the scale $(53.0 \%)$, while $12.2 \%$ were identified as centrist, and $24.8 \%$ were identified as rightwing conservative. Pearson's correlation was performed to examine the relation between PPRS dimensions and FACES IV dimensions, religiosity, political conservatism, and age at the time of $\mathrm{CO}$ (Table 2).

The correlations were found to be as expected, even if the strength of these correlations was weak to moderate. The strongest correlations have been found to be between the rigid $\left(\mathrm{r}_{\text {maternal }}=.47 ; \mathrm{r}_{\text {paternal }}=.55, p<.01\right)$ and enmeshed dimensions on FACES IV and the maternal and paternal reactions to $\mathrm{CO}\left(\mathrm{r}_{\text {maternal }}=.30 ; \mathrm{r}_{\text {paternal }}=.60\right.$, $p<.01)$. Also, a strong parents' political conservatism $\left(\mathrm{r}_{\text {paternal }}=.61, \quad p<.01 ; \quad \mathrm{r}_{\text {maternal }}=.34, \quad p<.01\right)$ and higher parents' religiosity involvement $\left(\mathrm{r}_{\text {maternal }}=.42\right.$, $p<.01)$ were correlated to a more negative reaction to $\mathrm{CO}$.

We conducted Pearson regression analysis in order to understand the reasons behind parental negative reaction. Item 2 "Was worried about what her friends and other parents would think of her/him"; item 7 "was concerned about the potential that she wouldn't get grandchildren from me" and item 12 "was concerned about having to answer other peoples' questions about my sexuality" were valued with the highest scores, both in paternal and maternal questionnaires. Table 3 shows the correlation between the highest items scores of PPRS and the FACES IV dimensions.

\section{Effect of Gender and Age of Child on Parental} Reactions

The average age of $\mathrm{CO}$ in the sample was $M=19.26$, $\mathrm{DS}=2.64$, ranged from 12 to 26 , Univariate Anova analysis shows no significative differences between women and men $\left(M_{\text {woman }}=18.9, S D=2.35 ; \quad M_{\text {men }}=19.56\right.$, $S D=2.83$ ). From the $\mathrm{CO}$ to the present survey have passed, on average, 4.6 years $(M=4.6, D S=2.90)$ with no significative differences between women and male $\left(M_{\text {woman }}=4.8, S D=2.71 ; M_{\text {men }}=4.42, S D=3.03\right)$.

Univariate analysis of covariance (ANCOVA) was used to examine the effects of gender of the son/daughter and the gender of the parent on parental reaction, using family global functioning and age of $\mathrm{CO}$ as covariate. Family functioning as a covariate was significant, with $F(1,322)=10.79, p<.001, \eta 2=.03$, as was the age at which the son/daughter did the CO: $F(1,322)=9.36$, $p<.01, \eta 2=.03$. A negative family functioning and a lower age of the son/daughter at the time of $\mathrm{CO}$ was 
positively related to a more negative parental reaction to CO.

We did not find a significant effect for gender of the son/daughter, $F(1,322)=1.13, p=.29, \eta 2=.003$, or the gender of the parents $F(1,322)=2.94, p=.09$, $\eta 2=.01$. The interaction of gender of the son/daughter $\times$ the gender of the parents was significant, $F(1$, $322)=26.12, p<.001, \eta 2=.08$. Mothers with a lesbian daughter $(M=92.46 ; S D=25.77)$ reported a more negative reaction to the $\mathrm{CO}$ than did fathers with a gay son $(M=84.50 ; S D=25.68)$. The parents of the other two groups (mothers with gay sons and father with lesbian daughters), which do not differ from each other, reported the most positive reactions (Duncan Test; $p<.05)$. The magnitude of the effect size was medium for the interaction effect, and low for the covariates. Table 4 shows the adjusted means, which are the means that we would get after removing all differences that can be accounted for by the covariates.
Table 4 Mean score on the Perceived Parental Reactions Scale: the interaction effect of gender of the son/daughter $\times$ gender of the parents

\begin{tabular}{llll}
\hline PPRS & Female & Malee & Total \\
\hline Mother & $92.46(25.78)$ & $74.78(25.66)$ & $83.62(25.89)$ \\
Father & $72.91(25.67)$ & $84.50(25.68)$ & $78.71(25.87)$ \\
\hline
\end{tabular}

$\mathrm{SD}$ in parenthesis

\section{Predictors of Negative Parental Reactions}

Next, using hierarchical multiple regression, we further examined the associations between demographic variables, religiosity, political involvement, family variables, and parents reactions to $\mathrm{CO}$. In the regression, we entered in the first step the gender of the son/daughter and the age of his/ her CO. Religious involvement and political orientation were entered in the second step, and the family variables, measured with the FACES-IV, in the third step(Table 5).

Table 2 Pearson correlation between variables

\begin{tabular}{|c|c|c|c|c|c|c|c|c|c|c|c|c|c|}
\hline & Variables & 1 & 2 & 3 & 4 & 5 & 6 & 7 & 8 & 9 & 10 & 11 & 12 \\
\hline 1 & Maternal reaction & 1 & & & & & & & & & & & \\
\hline 2 & Paternal reaction & $.52 * *$ & 1 & & & & & & & & & & \\
\hline 3 & Religiosity mother & $.42 * *$ & $.31 * *$ & 1 & & & & & & & & & \\
\hline 4 & Religiosity father & -.11 & .06 & -.13 & 1 & & & & & & & & \\
\hline 5 & Conservatism mother & $.20 * *$ & .03 & $.21 * *$ & $-.23 * *$ & 1 & & & & & & & \\
\hline 6 & Conservatism father & $.34 * *$ & $.61 * *$ & $.21 * *$ & -.05 & $.32 * *$ & 1 & & & & & & \\
\hline 7 & Cohesion & -.09 & -.14 & -.08 & -.12 & -.05 & $-.16^{*}$ & 1 & & & & & \\
\hline 8 & Flexibility & $-.20 *$ & -.15 & -.12 & -.08 & -.08 & $-.19 *$ & $.72 * *$ & 1 & & & & \\
\hline 9 & Disengaged family & .02 & $.20 * *$ & -.01 & .08 & .07 & $.27 * *$ & $-.50 * *$ & $-.25 * *$ & 1 & & & \\
\hline 10 & Enmeshed family & $.30 * *$ & $.60 * *$ & $.21 * *$ & -.09 & .10 & $.44 * *$ & -.03 & -.09 & $.19 *$ & 1 & & \\
\hline 11 & Rigid family & $.47 * *$ & $.55^{* *}$ & $.24 * *$ & .06 & -.06 & $.31 * *$ & -.07 & -.14 & .11 & $.60 * *$ & 1 & \\
\hline 12 & Chaotic family & -.01 & .07 & $-.16^{*}$ & -.06 & .07 & $.18^{*}$ & $-.18^{*}$ & -.05 & $.48 * *$ & $.21 * *$ & .02 & 1 \\
\hline
\end{tabular}

$* p<.05 ; * * p<.01$

Table 3 Pearson correlations between PPRS highest scored items and FACES IV dimensions

$* * p<.001 ; * p<.05$

\begin{tabular}{lllllll}
\hline $\begin{array}{l}\text { PPRS } \\
\text { items }\end{array}$ & M (DS) & $\begin{array}{l}\text { Item-total } \\
\text { score } \\
\text { correlation }\end{array}$ & Cohesion & Flexibility & Disengaged Enmeshed Rigid Chaotic \\
& & & & \\
\hline
\end{tabular}

Was worried about what her friends and other parents would think of her (item 2)

$\begin{array}{lrrrrrrrr}\text { Mother } & 3.14(1.39) & .62 * * & .00 & -.06 & .010 & .24 * * & .39 * * & -.02 \\ \text { Father } & 2.93(1.52) & .64 * * & -.04 & -.01 & .24 * * & .32 * * & .32 * * & .08\end{array}$

Was concerned about the potential that she/he wouldn't get grandchildren from me (item 7)

$\begin{array}{llllrrrrr}\text { Mother } & 3.55(1.17) & .57 * * & .04 & -.08 & -.08 & .26 * * & .38^{* *} & -.05 \\ \text { Father } & 3.14(1.33) & .54 * * & .05 & .04 & .00 & .27 * * & .42 * * & .01\end{array}$

Was concerned about having to answer other peoples' questions about my sexuality (item 12)

\begin{tabular}{llllllllr} 
Mother & $3.28(1.28)$ & $.56^{* *}$ & -.02 & -.10 & .12 & $.17 *$ & $.33^{* *}$ & -.01 \\
Father & $3.12(1.30)$ & $.75^{* *}$ & -.04 & -.06 & $.18^{*}$ & $.46^{* *}$ & $.43^{* *}$ & .07 \\
\hline
\end{tabular}


Table 5 Hierarchical regression analyses for family functioning predicting father and mother reaction to $\mathrm{CO}$
The tabled values for beta reflect Bs after step 3

$* p<.05 ; * * p<.001$

\begin{tabular}{|c|c|c|c|c|c|c|c|c|c|c|}
\hline & \multicolumn{4}{|l|}{ Mother } & \multirow[t]{2}{*}{$\Delta \mathrm{R}^{2}$} & \multicolumn{4}{|l|}{ Father } & \multirow[t]{2}{*}{$\Delta \mathrm{R} 2$} \\
\hline & $\mathrm{B}$ & $\begin{array}{l}\text { SE } \\
\text { B }\end{array}$ & $\beta$ & $\overline{\mathrm{R}^{2}}$ & & $\mathrm{~B}$ & $\begin{array}{l}\text { SE } \\
\text { B }\end{array}$ & $\beta$ & $\overline{\mathrm{R}^{2}}$ & \\
\hline Step 1: Gender and age & & & & .10 & .10 & & & & .22 & .22 \\
\hline $\begin{array}{l}\text { Gender }(0=\text { female } \\
\quad 1=\text { male })\end{array}$ & -18.42 & 3.44 & $-.33^{* *}$ & & & -1.64 & 3.25 & -.02 & & \\
\hline Age at coming out & -1.48 & 61 & $-.15 *$ & & & -2.39 & .59 & $-.25 * *$ & & \\
\hline $\begin{array}{l}\text { Step 2: Religiosity and } \\
\text { political ideology }\end{array}$ & & & & .34 & .24 & & & & .48 & .24 \\
\hline Religiosity & 2.84 & .55 & $.33 * *$ & & & .28 & .60 & .03 & & \\
\hline Political ideology & 6.03 & 1.96 & $.19 * *$ & & & 6.79 & 1.09 & $.37 * *$ & & \\
\hline Step 3: FACES IV subscales & & & & .48 & .24 & & & & .61 & .36 \\
\hline Cohesion & .36 & .40 & .09 & & & -.21 & .38 & -.05 & & \\
\hline Flexibility & -.65 & .43 & -.13 & & & -.02 & .42 & -.00 & & \\
\hline Disengaged family & .12 & .42 & .02 & & & .41 & .41 & .07 & & \\
\hline Enmeshed family & -.12 & .44 & -.02 & & & 1.7 & .44 & $.28 * *$ & & \\
\hline Rigid family & 1.9 & .38 & $.38 * *$ & & & .87 & .37 & $.16^{* * *}$ & & \\
\hline Chaotic family & -.38 & .40 & -.07 & & & -.81 & .38 & -.14 & & \\
\hline Total R & & & & .70 & & & & & .78 & \\
\hline
\end{tabular}

The analysis of the mother sample showed that a negative reaction to $\mathrm{CO}$ was predicted by the gender of the adolescent (having a lesbian daughter) $(\beta=.33, \mathrm{t}=5.36$, $p<.001)$, lower age at time of $\mathrm{CO}(\beta=.15, \mathrm{t}=-2.43$, $p<.05)$, a greater parents' religious involvement $(\beta=.33, \mathrm{t}=5.20, p<.001)$, a parents' right-wing political conservatism $(\beta=.19, \mathrm{t}=3.41, p<.01)$, and higher score in the scale Rigid of the FACES-IV $(\beta=.38$, $\mathrm{t}=4.92, p<.001)$. In the father sample, a worse reaction to the $\mathrm{CO}$ of the son/daughter, was predicted by a lower age of the adolescent at the $\operatorname{CO}(\beta=.25, t=4.09$, $p<.001$ ), a parents' right-wing political conservatism $(\beta=.37, \mathrm{t}=6.90, p<.001)$, and higher score in the scale Enmeshed $(\beta=.28, \mathrm{t}=3.93,<.001)$ and $\operatorname{Rigid}(\beta=.16$, $\mathrm{t}=2.35, p<.05)$.

\section{Discussion}

The present research aimed to analyze the variables connected with perceived parental reactions to their child's CO. To assess participants' perceptions of their parents' reactions, we administered the Perceived Parental Reactions Scale, from which no significant differences were found in maternal and paternal reactions in the same family. This result is inconsistent with the literature, which suggests that mothers' reactions are more negative than fathers', as has been seen in Willoughby and colleagues' work (Willoughby et al. 2006); both scores suggesting the tendency for Italian parents to react more positively to the $\mathrm{CO}$ of their children, then parents in Willoughby and colleagues' sample (Willoughby et al. 2006). Future studies should verify these findings, especially in Italy; according to cross-cultural studies, Italian mothers are more warm and protective towards their children than are women from other countries (Putnick et al. 2012), which may have some bearing on an Italian mother's reaction to her child's CO.

However, despite not finding significant differences between perceived maternal and paternal reactions to $\mathrm{CO}$, differences were found in the ways parents discovered the sexual orientation of their sons/daughters (Table 1). Daughters and sons were more inclined to directly come out to their mothers versus their fathers, who appear to find out more indirectly. According to the literature, disclosure is a process that occurs in different stages, and $\mathrm{CO}$ to parents (D'Augelli 1994) is one of them. Revealing sexual orientation to parents, according to Eriksson model (1982), could bean important task to develop a healthy personality, to differentiate from parents and to win fears. However, the female parent seems to be the "chosen one" in the light of the trustful relationship that daughters and sons feel they have with their mothers (Miller and Boon 1999). That being so, a maternal negative reaction could strongly affect the adolescent's self-esteem and force him/her to assume a negative self-image, in addition to undermines the motherchild relationship (Waldner and Magrader 1999).

Nonetheless, as shown in Table 1, it appears frequently that parents discovered their daughter's and son's sexual identity by themselves, maybe this could lead to a more negative reaction, as parents can read the lack of honesty as a lack of trust, or again they can have doubts, worries and 
being ashamed to talk about that with their sons and daughters.

Results reported in Table 2 show a correlation between a negative perceived maternal and paternal response and a parents' perceived right-wing conservative political view; the same correlation has been found between maternal negative reaction and parents' strong religious involvement. These data, in line with the literature (Newman and Muzzonigro 1993; Schope 2002), suggest that believing in conservative traditional values can be a predictor of sexual prejudice. In countries such as Italy, where religious feelings are ingrained in the culture, it is not unusual for LGBT people to experienced religion-based homophobia (Baiocco and Laghi 2013; Cartabia 2008; Herek 2000; Lingiardi et al. 2005, 2012); these experiences can prevent or delay the disclosure for fear of rejection. This result deserves to be analyzed more deeply. As has been seen, mothers with higher levels of religious belief and fathers with strong conservatism and right-wing political views are more likely to react in a negative way. In Italy, it is a cultural given that mothers are the ones who take care of the house, which can be seen as the "private-family thing," while fathers have the tendency to be concerned with the "public-social thing," e.g., politics. Women, in the past, were not supposed to participate in political debates or go into politics, but they were responsible for the religious education of their daughters and sons. It is likely that in the more conservative families, aspects of this legacy remain, and this cultural phenomenon can explain current findings (Jurado Guerrero and Naldini 1996).

Concerning the relationship between a negative parental reaction and FACES IV dimensions, the data in Table 2 show a strong correlation with enmeshed dimensions for both parents. These results, along with the literature (Baiocco et al. 2013a; De Vine 1984; Willoughby et al. 2006), support the hypothesis that poor family functioning (lack of adaptability, no coping ability, poor resilience resources, lack of communication) is predictive of a negative parental reaction to the adolescent/young adult's CO. The disclosure about sexual orientation in an enmeshed family could be difficult for several reasons: the strong bonds between the family's members can limit the individual growth and choices, so much so that almost any expression of independence or separateness is seen as disloyalty to the family. Highly enmeshed families are likely to have highly emotional interactions and the revelation can generate strong feeling of delusion in overly dependent parents and, as a consequence, feelings of guilty in their daughters and sons (Baiocco et al. 2013a). Or, again, the parent's identity could be so wrapped up in their child's identity that makes the acceptance of the disclosure really complicated. Table 3 shows the correlations between the highest PPRS' items scores and the family functioning. Three Item 2, item
7 and item 12 have been valued with the highest scores both for fathers and mothers. These data suggest that both parents are worried about what other people, friends and relatives could think about their sons and daughters sexuality (item 2 and 7): These items could reflect deep feelings of shame about having a homosexual daughter or son; parents can fear the judgment of others people, maybe about their parental skills and they are afraid to speak about that. These items shows higher correlations with Enmeshed and Rigid family functioning, along with the results already presented: In these family it seems fundamental to keep the appearance from the outside, and it is possible that they prefer to keep the disclosure inside the family, and not mention about it to friends or others relatives (as it has been seen in Rivers and Gordon 2010). Item 12 is more cultural related, and reflect the belief that only a couple formed by a men and woman can have children and, as a consequence, it opens a narcissistic wound in the parents who see their desire to become grandparents fading away.

According to our results, the age of the son/daughter at the time of $\mathrm{CO}$ is an important predictor of parental reaction. The lower the age of the participants at the time of $\mathrm{CO}$, the worse the reaction of both parents, which confirms our hypothesis (D’Augelli 2006; LaSala 2000; Saltzburg 2004; Savin-Williams 2001). ANCOVA analysis reveals that both parents react worst to same-gender adolescents' disclosure. From a paternal point of view, the $\mathrm{CO}$ of a male son can be seen as a failure to successfully pass on masculinity, and fathers can feel deepening feelings of shame, which make them unwilling to discuss the disclosure and participate emotionally in the event (LaSala 2010). Furthermore, the analysis of the interaction between son/ daughter and parental gender shows that mothers with a lesbian daughter display a more negative reaction to the disclosure than do fathers with a gay son. According to Pearlman (2012), who has collected 24 stories of mothers with lesbian and transgender daughters, the maternal reaction seems to be so negative because of the hurt and disappointment as they see all their dreams for their daughter's future unravel; this is followed by feelings of loss of the mother-daughter bond, which they now feel more as a mother-son relationship (Pearlman 2012). Or, as already said, mothers where also responsible for the emotional socialization of their daughters and sons, homosexuality could be seen as a failure in this task and they "blame" themselves for that. Nevertheless, as the present research is focus on the participants perception of their parents reaction, there is an interesting explanation for this phenomena given by Chiari. According to her data, lesbian daughter tend to ascribe feeling of disapproval to their mother and feelings of worry to their fathers, more than male sons: This could be an effect of interpersonal dynamics of identification and projection with their 
reference parental figure. The young lesbian daughter perceives a more negative maternal reaction due to the gap between herself and the object of identification, and, as a consequence of this process, she overestimates the disapproval reaction (Chiari 2006).

The association between sex, age, religiosity, political involvement, and family dimensions has been examined through step-wise hierarchical multiple regression in order to identify the predictors of parental negative reaction (Table 5). Maternal negative response is mostly predicted by: having a lesbian daughter, the age at the time $\mathrm{CO}$, religious association, and a right-wing conservative political view. On the other hand, paternal negative response is mostly predicted by a lower age of the son at the time of $\mathrm{CO}$ and right-wing political conservatism.

Both maternal and paternal negative reaction are connected to a higher score in the Rigid scale of the FACES IV (mother $\beta=.38, \mathrm{t}=4.92, p<.001 ;$ father $\beta=.16$, $\mathrm{t}=2.35, p<.05)$. According to the literature, rigid families are characterized by overly low levels of flexibility and adaptability, which are the family's main resources to face stressful and unexpected situations and keep the internal cohesion (Mathis and Tanner 1991; James and Hunsley 1995). Our results reveal, moreover, that a negative parental reaction is also predicted by a higher score on the FACES IV enmeshed scale $(\beta=.28, t=3.93, p<.001)$, which is characterized by higher levels of cohesion, an extreme amount of emotional closeness, and strong demands on loyalty. In this situation, the disclosure can be seen as an unexpected betrayal of the expectation and values of the family. These results suggest that when the family is dysfunctional and displays strong boundaries-related problems, the parental reaction to $\mathrm{CO}$ can be extremely negative.

The inability to reframe perceptions, ideas, and information about their son/daughter, can damage the family's bonds, leading to, on one hand, losing marital stability and, on the other hand, make the child feel guilt and rejection (Olson and Lavee 2013; Willoughby et al. 2008). For an adolescent/young adult who decides to reveal his or her same-sex attraction under these conditions, internalizing the minority sexual stigma could be a concrete possibility, the negative consequences of which are well known in the literature (Frost et al. 2013; Willoughby et al. 2008).

In conclusion, our findings confirm that a negative parental reaction results from poor family resources to face a stressful situation, a strong belief in traditional values, a lower age at time of $\mathrm{CO}$, and - for mothers-having a lesbian daughter. These results have important implications in both clinical and social fields. First of all, in therapeutic and counseling assessment, it is fundamental to understand these variables when focusing the intervention, in order to prevent a negative parental reaction to $\mathrm{CO}$ on one hand, and on the other hand to help the family to accept the disclosure and readjust the family's boundaries. Also, when the social group and the family have strong religious affiliations and particularly conservative political views, a message of homophobia has been internalized, and this can jeopardize the process of acceptance of the disclosure. Due to their social importance, these results can be tested also in other southern Europe regions, where the cultural values are similar to Italian's one. Nevertheless, disclosing to family about sexual identity is an important step for every young LG, and these findings could be helpful for social and clinical workers in every Country. Homophobia and social marginalization of adolescents and young adults is still a reality in Italy, and we hope that our findings can help family therapists, counselors, and educators create a supportive and welcoming environment to daughters and sons who decide to take the difficult choice of $\mathrm{CO}$.

\section{Limitations}

There were a few limitations to our study. First the sample was relatively small; a larger and more representative sample should be studied to obtain more stable results. The study was conducted in Italy, and these findings may not apply to LG males living in other countries, since our data appear to be strongly related to our culture. Also, the use of a convenience sample can never truly access a representative sample of LG individuals. The sample was composed by young adults, it would be interesting to investigate the experience of adults and older people, in different times of life. Moreover there could have been some bias regarding the perception of negative parental reaction, maybe perceived as more negative than it actually was. In this regard it would be interesting to take a longitudinal study, in order to analyze whether the time elapsed since the $\mathrm{CO}$, has a particular influence on parental reaction's perception. Finally, the study did not consider bisexual participants, once again due to the low number in our sample; likewise, it is necessary to explore how the $\mathrm{CO}$ of bisexual adolescents is perceived by their parents, and to verify if the differences between maternal and paternal reactions are the same as for the homosexual sample.

\section{References}

Armesto, J. C., \& Weisman, A. G. (2001). Attributions and emotional reactions to the identity disclosure ("coming out") of a homosexual child. Family Process, 40, 145-161.

Baiocco, R., Cacioppo, M., Laghi, F., \& Tafà, M. (2013a). Factorial and construct validity of FACES IV among Italian adolescents. Journal of Child and Family Studies, 22, 962-970.

Baiocco, R., D’Alessio, M., \& Laghi, F. (2010). Binge drinking among gay, and lesbian youths: The role of internalized sexual stigma, self-disclosure, and individuals' sense of connectedness to the gay community. Addictive Behaviors, 35, 896-899. 
Baiocco, R., \& Laghi, F. (2013). Sexual orientation and the desires and intentions to become parents. Journal of Family Studies, 19(1), 90-98.

Baiocco, R., Laghi, F., Di Pomponio, I., \& Nigito, C. S. (2012). Selfdisclosure to the best friend: Friendship quality and internalized sexual stigma in Italian lesbian and gay adolescents. Journal of adolescence, 35(2), 381-387.

Baiocco, R., Nardelli, N., Pezzuti, L., \& Lingiardi, V. (2013b). Attitudes of Italian heterosexual older adults towards lesbian and gay parents. Sexuality Research and Social Policy, 10, 285-292.

Baptist, J. A., \& Allen, K. R. (2008). A family's coming out process: Systemic change, and multiple realities. Contemporary Family Therapy, 30, 92-110.

Ben-Ari, A. (1995). The discovery that an offspring is gay: Parents', gay men's, and lesbians' perspectives. Journal of Homosexuality, 30, 89-112.

Bos, H. M. W., Van Balen, F., \& Van Den Boom, D. C. (2004). Experience of parenthood, couple relationship, social support, and child-rearing goals in planned lesbian mother families. Journal of Child Psychology and Psychiatry, 45, 755-764.

Boxer, A. M., Cook, J. A., \& Herdt, G. (1991). Double jeopardy: Identity transitions and parent-child relations among gay and lesbian youth. In K. Pillemer \& K. McCartney (Eds.), Parentchild relations throughout life (pp. 59-92). Hillsdale, NJ: Lawrence Erlbaum.

Carnelley, K. B., Hepper, E. G., Hichs, C., \& Turner, W. (2011). Perceived parental reactions to coming out, attachment, and romantic relationship views. Attachment and human development, 13, 217-236.

Cartabia, M. (2008). Legal study on homophobia and discrimination on grounds of sexual orientation in Italy. Vienna: European Union Agency for Fundamental Rights.

Cass, V. (1979). Homosexual identity formation: A theoretical model. The Journal of Homosexuality, 4, 219-235.

Chaudoir, S. R., \& Fisher, J. D. (2010). The disclosure processes model: Understanding disclosure decision making and post disclosure outcomes among people living with a concealable stigmatized identity. Psychological Bulletin, 136, 236-256.

Chiari, C. (2006). La famiglia attraverso lo svelamento. In D. Rizzo (Ed.), Omosapiens (pp. 10-21). Roma: Carocci Editore.

Conley, C. L. (2011). Learning about a child's gay or lesbian sexual orientation: Parental concerns about societal rejection, loss of loved ones, and child well being. Journal of Homosexuality, 58, 1022-1040.

Cramer, D. W., \& Roach, A. J. (1988). Coming out to mom and dad: A study of gay males and their relationships with their parents. Journal of Homosexuality, 15, 79-91.

D'Augelli, A. R. (2006). Developmental and contextual factors and mental health among lesbian gay and bisexual youths. In A. E. Omoto \& H. M. Kurtzman (Eds.), Sexual orientation and mental health: Examining identity and development in lesbian, gay, and bisexual people (pp. 37-53). Washington, DC: APA Books.

D'Augelli, A. R., \& Grossman, A. H. (2001). Disclosure of sexual orientation, victimization and mental health among lesbian, gay and bisexual older adults. Journal of Interpersonal Violence, 16, 1008-1027.

D’Augelli, A. R., \& Hershberger, S. L. (1993). Lesbian, gay, and bisexual youth in community settings: Personal challenges and mental health problems. American Journal of Community Psychology, 21, 421-448.

D'Augelli, A. R., Pilkington, N. W., \& Hershberger, S. L. (2002). Incidence and mental health impact of sexual orientation victimization of lesbian, gay and bisexual youths in high school. School Psychology Quarterly, 17, 148-167.
D'Augelli, A. R. (1994). Identity development and sexual orientation: Toward a model of lesbian, gay, and bisexual development. In E. J. Trickett, R. J. Watts \& D. Birman (Eds.), Human diversity: Perspectives on people in context. The Jossey-Bass social and behavioral science series (pp. 312-333). San Francisco, CA, US.

D’Augelli, R., Grossman, A. H., \& Starks, M. T. (2005). Parents' awareness of lesbian, gay, and bisexual youths' sexual orientation. Journal of Marriage and Family, 67, 474-482.

D'augelli, A. R., Grossman, A. H., \& Starks, M. T. (2008). Families of gay, lesbian, and bisexual youth: What do parents and siblings know and how do they react? Journal of GLBT Family Studies, 4(1), 95-115.

De Vine, J. L. (1984). A systemic inspection of affectional preference orientation and the family of origin. Journal of Social Work and Human Sexuality, 2, 9-17.

Erikson, E. H. (1959). Identity and the life cycle. New York: International Universities Press.

Erikson, E. H. (1982). The cycle life completed. New York: Norton.

Frost, D. M., Lehavot, K., \& Meyer, I. H. (2013). Minority stress and physical health among sexual minority individuals. Journal of behavioral medicine, 36(6), 1-8.

Gardner, A. T., de Vries, B., \& Mockus, D. S. (2014). Aging out in the desert: Disclosure, acceptance, and service use among midlife and older lesbians and gay men. Journal of Homosexuality, 61(1), 129-144.

Green, R. J. (2000). "Lesbians, gay men, and their parents": A critique of La Sala and the prevailing clinical "wisdom". Family Process, 39, 257-266.

Guzzo, G., Lo Cascio, V., \& Pace, U., et al. (2014). Bullying victimization, post-traumatic symptoms, and the mediating role of alexithymia. Child Indicator Research, 7, 141-153.

Heatherington, L., \& Lavner, J. A. (2008). Coming to term with coming out: Review and recommendation for family systemfocused research. Journal of Family Psychology, 22, 329-343.

Henry, M. M. (2013). Coming out: Implications for self-esteem and depression in gay and lesbian individuals (Doctoral dissertation, Humboldt State University).

Herek, G. M. (2000). Sexual prejudice and gender: Do heterosexuals' attitudes toward lesbian and gay men differ? Journal of Social Issues, 56, 251-266.

Herek, G. M., \& Garnets, L. D. (2007). Sexual orientation and mental health. Annual Review of Clinical Psychology, 3, 353-375.

Hoffman, N. D., Freeman, K., \& Swann, S. (2009). Healthcare preferences of lesbian, gay, bisexual, transgender and questioning youth. Journal of Adolescent Health, 45(3), 222-229.

James, S., \& Hunsley, J. (1995). The Marital Adaptability and Cohesion Evaluation Scale III: Is the relation with marital adjustment linear or curvilinear? Journal of Family Psychology, 9, 458-462.

Jurado Guerrero, T., \& Naldini, M. (1996). Is the South so different? Italian and Spanish families in comparative perspective. South European Society and Politics, 1(3), 42-66.

Kinsey, A. C., Pomeroy, W. B., \& Martin, C. E. (1948). Sexual behaviour in the human male. Philadelphia, PA: Saunders.

LaSala, M. C. (2000). Lesbian, gay men, and their parents: Family therapy for the coming-out crisis. Family Process, 39, 67-81.

LaSala, M. C. (2010). Coming out, coming home: Helping families adjust to a gay or lesbian child. New York: Columbia University Press.

Lavee, Y., \& Olson, D. H. (1991). Family types and response to stress. Journal of Marriage and the Family, 53(3), 786-798.

Legate, N., Ryan, R. M., \& Weinstein, N. (2012). Is coming out always a "good thing"? Exploring the relations of autonomy support, outness, and wellness for lesbian, gay, and bisexual individuals. Social Psychological and Personality Science, 3(2), $145-152$. 
Lingiardi, V., Baiocco, R., \& Nardelli, N. (2012). Measure of internalized sexual stigma for lesbians and gay men: A new scale. Journal of Homosexuality, 59, 1191-1210.

Lingiardi, V., Falanga, S., \& D'Augelli, A. (2005). The evaluation of homophobia in a Italian sample. Archives of Sexual Behavior, 34, 81-93.

Lo Cascio, V., Guzzo, G., Pace, F., \& Pace, U. (2013). Anxiety and self-esteem as mediators of the relation between family communication and indecisiveness in adolescence. International Journal for Educational and Vocational Guidance, 13(2), 135-149. doi:10.1007/s10775-013-9243-1.

Maguen, S., Floyd, F. G., Bakeman, R., \& Armistead, L. (2002). Developmental milestones and disclosure of sexual orientation among gay, lesbian, and bisexual youths. Applied Developmental Psychology, 23, 219-233.

Mathis, R. D., \& Tanner, Z. (1991). Cohesion, adaptability, and satisfaction of family systems in later life. Family Therapy, 18, $47-60$.

Meyer, I. H. (1995). Minority stress and mental health in gay men. Journal of Health and Social Behavior, 36, 38-56.

Meyer, I. H. (2003). Prejudice, social stress, and mental health in lesbian, gay, and bisexual populations: Conceptual issues and research evidence. Psychological Bulletin, 129, 674-697.

Miller, R. J., \& Boon, S. D. (1999). Trust and disclosure of sexual orientation in gay males' mother-son relationships. Journal of Homosexuality, 38(3), 41-63.

Mohr, J. J., \& Fassinger, R. E. (2003). Self-acceptance and selfdisclosure of sexual orientation in lesbian, gay and bisexual adults: An attachment perspective. Journal of Counselling Psychology, 50, 482-495.

Newman, B. S., \& Muzzonigro, P. G. (1993). The effects of traditional family values on the coming out process of gay male adolescents. Adolescence, 28, 213-226.

Olson, D. H. (2011). FACES IV and the circumplex model: Validation study. Journal of Marital and Family Therapy, 3, 64-80.

Olson, D. H., \& Gorall, D. M. (2006). Faces IV and the circumplex model. Minneapolis, MN: Life Innovations.

Olson, D. H., \& Lavee, Y. (2013). Family systems and family stress: A family life cycle. In K. Kreppner \& R. M. Lerner (Eds.), Family Systems and Life-span Development (pp. 165-196). New York, NY: Psychology Press.

Pace, U., Cacioppo, M., \& Schimmenti, A. (2012). The moderating role of father's care on the onset of binge eating symptoms among female late adolescents with insecure attachment. Child Psychiatry and Human Development, 43, 282-292.

Pallini, S., \& Laghi, F. (2012). Attention and attachment related behaviour toward professional caregivers in child care centers: A new measure for toddlers. The Journal of Genetic Psychology, 173(2), 158-174.

Patterson, J. M. (2002). Integrating family resilience and family stress theory. Journal of Marriage and Family, 64(2), 349-360.

Pearlman, Sarah. F. (2012). Mother-talk: Conversations with mothers of lesbian daughters and FTM transgender children. Toronto, ON: Demeter Press.

Putnick, D. L., Bornstein, M. H., Lansford, J. E., Chang, L., DeaterDeckard, K., Di Giunta, L., et al. (2012). Agreement in mother and father acceptance-rejection, warmth, and hostility/rejection/ neglect of children across nine countries. Cross-Cultural Research, 46(3), 191-223.
Resnick, M. D., Bearman, P. S., Blum, R. W., Bauman, K. E., Harris, K. M., Jones, J., et al. (1997). Protecting adolescents from harm. Findings from the national longitudinal study on adolescent health. Journal of the American Medical Association, 278(10), 823-832.

Rivers, I., \& Gordon, K. (2010). 'Coming out', context and reason: First disclosure of sexual orientation and its consequences. Psychology \& Sexuality, 1(1), 21-33.

Roth, D. L., Mwase, I., Holt, C. L., Clark, E. M., Lukwago, S., \& Kreuter, M. W. (2012). Religious involvement measurement model in a national sample of African Americans. Journal of Religion and Health, 51, 567-578.

Russell, S. T. (2003). Sexual minority youth and suicide risk. American Behavioral Scientist, 46, 1241-1257.

Ryan, C., Huebner, D., Diaz, R. M., \& Sanchez, J. (2009). Family rejection as a predictor of negative health outcomes in white and Latino lesbian, gay, and bisexual young adults. Pediatrics, 123(1), 346-352.

Ryan, C., Russell, S. T., Huebner, D., Diaz, R., \& Sanchez, J. (2010). Family acceptance in adolescence and the health of LGBT young adults. Journal of Child and Adolescent Psychiatric Nursing, 23, 205-213.

Sakalli, N. (2002). Application of the attribution-value model of prejudice to homosexuality. The Journal of Social Psychology, $142(2), 264-271$.

Saltzburg, S. (2004). Learning that an adolescent child is gay or lesbian: The parent experience. Social Work, 49, 109-118.

Savin-Williams, R. C. (2001). Mom, dad. I'm gay: How families negotiate coming out. Washington, DC: American Psychological Association.

Savin-Williams, R. C. (2005). The new gay teenager. Cambridge, MA: Harvard University Press.

Savin-Williams, R. C., \& Dube, E. M. (1998). Parental reaction to their child's disclosure of a gay/lesbian identity. Family Relations, 47, 7-13.

Savin-Williams, R. C., \& Ream, G. L. (2003). Sex variations in the disclosure to parents of same-sex attractions. Journal of Family Psychology, 17, 429-438.

Schope, R. D. (2002). The decision to tell: Factors influencing the disclosure of sexual orientation by gay men. Journal of Gay and Lesbian Social Services: Issues in Practice, Policy, and Research, 14, 1-22.

Shilo, G., \& Savaya, R. (2011). Effects of family and friend support on LGB youths mental health and sexual orientation milestones. Family Relations, 60, 318-330.

Vaughan, M. D., \& Waehler, C. A. (2010). Coming out growth: Conceptualizing and measuring stress-related growth associated with coming out to others as a sexual minority. Journal of Adult Development, 17, 94-109.

Waldner, L. K., \& Magrader, B. (1999). Coming out to parents. Journal of Homosexuality, 37, 83-100.

Willoughby, B. L., Doty, N. D., \& Malik, N. M. (2008). Parental reactions to their child's sexual orientation disclosure: A family stress perspective. Parenting: Science and Practice, 8(1), 70-91.

Willoughby, B. L., Doty, N. D., \& Malik, N. M. (2010). Victimization, family rejection, and outcomes of gay, lesbian, and bisexual young people: The role of negative GLB identity. Journal of GLBT Family Studies, 6(4), 403-424.

Willoughby, B. L. B., Malik, N. M., \& Lindahl, K. M. (2006). Parental reactions to their sons' sexual orientation disclosures: The roles of family cohesion, adaptability and parenting style. Psychology of Men and Masculinity, 7, 14-26. 